REGARDS

SUR L'ECONOMIE ALLEMANDE

BULLETIN ECONOMIQUE DU CRAC

\section{Regards sur l'économie allemande}

Bulletin économique du CIRAC

$67 \mid 2004$

Varia

\title{
Publicité : un marché à maturité plutôt qu'en crise
}

Isabelle Bourgeois

\section{OpenEdition}

\section{Journals}

Édition électronique

URL : http://journals.openedition.org/rea/3808

DOI : 10.4000/rea.3808

ISBN : 978-2-8218-0830-0

ISSN : 1965-0787

Éditeur

CIRAC

Édition imprimée

Date de publication : 1 juillet 2004

Pagination : 33-34

ISSN : 1156-8992

Référence électronique

Isabelle Bourgeois, "Publicité : un marché à maturité plutôt qu'en crise », Regards sur l'économie allemande [En ligne], 67 | juillet 2004, mis en ligne le 08 octobre 2009, consulté le 15 septembre 2020 URL : http://journals.openedition.org/rea/3808

Ce document a été généré automatiquement le 15 septembre 2020

(C) CIRAC 


\title{
Publicité : un marché à maturité plutôt qu'en crise
}

\author{
Isabelle Bourgeois
}

\section{Fin de la crise publicitaire pour 2004 ?}

1 Le marché publicitaire allemand pourrait bientôt sortir de la 'crise'. Avec 28,91 milliards $€$ en 2003, les investissements publicitaires bruts étaient certes inférieurs à leur niveau de 2002, mais leur recul (-2,6\%) s'est nettement ralenti en comparaison des années précédentes. En 2004, la situation ne devrait pourtant pas encore s'améliorer de manière significative $(+1,5 \%)$, estime la fédération allemande de la publicité Zentralverband der deutschen Werbewirtschaft (ZAW), la faiblesse de la conjoncture freinant toujours l'activité publicitaire. En 2003, la part des investissements publicitaires est tombée à $1,36 \%$ du PIB - soit le niveau historiquement le plus bas depuis 1978. Jusqu'ici, cette part atteignait bon an, mal an, quelque 1,6 \%.

Evolution des investissements publicitaires 1999-2003 (en milliards $€$ ) *)

\begin{tabular}{|l|c|c|c|c|c|}
\hline & $\mathbf{1 9 9 9}$ & $\mathbf{2 0 0 0}$ & $\mathbf{2 0 0 1}$ & $\mathbf{2 0 0 2}$ & $\mathbf{2 0 0 3}$ \\
\hline Total investissements bruts & 31,34 & 33,21 & 31,49 & 29,69 & 28,91 \\
\hline \hline Variation/ année précédente & $+4,2 \%$ & $+5,7 \%$ & $-5,2 \%$ & $-5,7 \%$ & $-2,6 \%$ \\
\hline Recettes pub. nettes des supports & 21,82 & 23,38 & 21,72 & 20,14 & 19,28 \\
\hline \hline Variation/ année précédente & $+4,9 \%$ & $+7,1 \%$ & $-7,1 \%$ & $-7,3 \%$ & $-4,3 \%$ \\
\hline
\end{tabular}

Source des données : Zentralverband der deutschen Werbewirtschaft (ZAW), 2004. *) valeur nominale, chiffres arrondis. 


\section{Forte baisse du support médias depuis 2001}

2 Depuis 2001, les médias ont vu leurs recettes baisser de $-17 \%$, soit un manque à gagner de 4,1 milliards $€$ qu'il leur sera d'autant plus difficile à combler que leurs dépenses d'autopromotion se sont considérablement accrues dans le même temps, signe d'une bataille acharnée autour du gâteau publicitaire. Parmi les supports, ce sont les quotidiens qui ont le plus été mis à mal (voir REA 66/04). A l'opposé, les sites Internet ont enregistré la plus forte progression, reflet du redéploiement des annonceurs vers le Web (et ses tarifs plus avantageux) en même temps que ce nouveau mode de communication s'est diffusé. Mais l'efficience de la publicité en ligne se laissant encore mal mesurer, l'enthousiasme pour ce support a quelque peu tiédi en attendant des outils de mesure plus fiable.

Evolution annuelle des recettes publicitaires nettes par support (en millions $€$ *)

\begin{tabular}{|c|c|c|c|c|c|c|c|c|}
\hline & 2000 & $\%$ & 2001 & $\%$ & 2002 & $\%$ & 2003 & $\%$ \\
\hline Quotidiens & 6557 & $+8,1$ & 5642 & $-14,0$ & 4937 & $-12,5$ & 4455 & $-9,8$ \\
\hline TV & 4709 & $+9,1$ & 4469 & $-5,1$ & 3956 & $-11,5$ & 3811 & $-3,7$ \\
\hline Publipostage & 3383 & $+2,2$ & 3256 & $-3,7$ & | 3335 & $+2,4$ & 3304 & $-1,0$ \\
\hline Périodiques & 2247 & $+12,0$ & 2092 & $-6,9$ & 1935 & $-7,5$ & 1861 & $-3,8$ \\
\hline Gratuits ${ }^{\text {a) }}$ & 1792 & $+2,8$ & 1751 & $-2,3$ & 1702 & $-2,8$ & 1746 & $+2,6$ \\
\hline Annuaires & 1268 & $+3,3$ & 1269 & $+0,1$ & 1250 & $-1,5$ & 1220 & $-2,4$ \\
\hline Presse prof. b) & 1267 & $+6,5$ & 1074 & $-15,2$ & 966 & $-10,1$ & 880 & $-8,9$ \\
\hline Affichage & 746 & $+9,5$ & 760 & $+1,8$ & 713 & $-6,1$ & 710 & $-0,5$ \\
\hline Radio & 733 & $+6,1$ & 678 & $-7,5$ & 595 & $-12,2$ & 579 & $-2,7$ \\
\hline Internet & 153 & +100 & 185 & $+20,6$ & 227 & $+22,7$ & 246 & $+8,4$ \\
\hline Hebdos ${ }^{c)}$ & 278 & $+6,2$ & 287 & $+3,3^{d)}$ & 268 & $-6,6$ & 225 & -e) \\
\hline Cinéma & 175 & $+1,6$ & 170 & $-2,8$ & 161 & $-5,7$ & 161 & $+0,1$ \\
\hline Suppléments & 68 & $-7,8$ & $89^{c}$ & - & 97 & $+8,2$ & 85 & $-11,7$ \\
\hline Total ${ }^{f)}$ & 23380 & $+7,1$ & 21723 & $-7,1$ & 20141 & $-7,3$ & 19280 & $-4,3$ \\
\hline
\end{tabular}

Source : ZAW, 2004. *) chiffres arrondis ; a) annonces ; b) et spécialisée ; c) et septième jour ; d) donnée non comparable avec les précédentes du fait d'un changement de périmètre de la catégorie e) comparaison annuelle impossible, un éditeur ayant fait une déclaration erronée et l'anonymat des déclarations à la ZAW interdisant toute correction rétroactive ; f) depuis 2001, déclaration cumulée des recettes publicitaires et des recettes issues de la distribution des suppléments. 


\section{Annonceurs : Aldi et Lidl en tête}

3 Au total, tous supports confondus, la décrue des recettes se ralentit désormais. Mais le volume des recettes publicitaires demeure inférieur à son niveau de 1999. 2000 ayant été une année exceptionnelle, la baisse semble brutale. Elle reflète en partie le tassement conjoncturel, comme l'indique le recul de la publicité institutionnelle dans les médias traditionnels (une tendance qui se poursuit sur les 4 premiers mois de 2004 avec $-13,1 \%$ selon les calculs de Nielsen Media), mais aussi la faiblesse de la consommation. Ainsi, la baisse (-2,2\% sur la même période) des investissements publicitaires de l'automobile, annonceur traditionnellement en tête, suit le tassement des immatriculations. Parmi les marques, la forte hausse de la promotion des enseignes Lidl $(+26,2 \%)$ et Aldi $(+38,9 \%)$, toutes deux en tête du palmarès, traduit une concurrence avivée dans la distribution alimentaire par la stagnation de la consommation des ménages.

\section{A la découverte d'une nouvelle cible : les + de 50 ans}

Mais la chute des investissements publicitaires depuis 2000 s'explique plus encore par la phase de consolidation d'un marché médiatique proche de la saturation. Après une décennie d'effervescence liée à la démultiplication des supports et à la rapide croissance du marché, l'économie publicitaire se stabilise maintenant. Les investissements publicitaires se redéploient donc entre les différents supports. Et les annonceurs sont à l'affût de nouvelles cibles. Ainsi, ils commencent, certes timidement encore, à 'découvrir' les plus de 50 ans, un groupe délaissé jusqu'ici mais que le débat public sur le vieillissement démographique met sur le devant de la scène. Par ailleurs, l'élargissement de l'UE, ainsi que l'accélération de l'intégration du marché communautaire, devraient dynamiser un secteur encore largement confiné dans les frontières nationales. Selon la fédération ZAW, les branches qui devraient dès lors le plus investir en 2004 sont: les télécommunications, le tourisme, l'assurance, les services financiers et la pharmacie (médicaments en vente libre). (IB)

\section{INDEX}

Mots-clés : publicité, marché, média, crise 